\title{
LEUCEMIA LINFOMA DE CELULAS T DEL ADULTO Y LINFOMA CUTANEO ASOCIADOS AL HTLV-1
}

\author{
Max Michele Remón-Torres ${ }^{1,2, a}$, Max Albert Remón-Torres ${ }^{1,2, a}$
}

1. Facultad de Medicina, Universidad Nacional San Luis Gonzaga. Ica, Perú.

2. Sociedad Científica de Estudiantes de Medicina de Ica.

b. Estudiante de medicina.

\section{RESUMEN}

El virus linfotrópico humano tipo 1 (HTLV-1) se adquiere a través de la lactancia prolongada, contacto sexual e infusión sanguínea, entre el 1-4\% de los infectados desarrollan Linfoma Leucemia de Células T del Adulto (LLCTA) con un periodo de latencia entre 30 y 50 años, siendo incurable y mortal a corto plazo, las causas de muerte más frecuentes son infecciones, el linfoma cutáneo de células T es otra manifestación del virus, indicando diseminación. Se presenta el caso de un hombre de 51 años, con hiporexia, odinofagia, lesiones ulceradas necróticas en manos, tórax y cabeza, micosis oral, ingresa por hematemesis, hematoquecia y astenia, presenta, anemia, alteraciones nutricionales y neurológicas. El estudio hematológico diagnosticó LLCTA y la biopsia linfoma cutáneo de células T. El paciente tendría un pronóstico desfavorable.

(Rev. méd. panacea 2011; 1:89-93).

Palabras Clave: Leucemia linfoma de Células T adulto, HTLV-1, linfoma cutáneo.

\section{ADULT T-CELL LEUKEMIA /LYMPHOMA AND CUTANEOUS LYMPHOMA ASSOCIATED TO HTLV -1}

\begin{abstract}
The human virus T-lymph trophic (HTLV-1) is acquired through prolonged breastfeeding, sexual contact and blood infusion. Between $1 \%$ to $4 \%$ of those infected, develop Adult T-cell leukemia/lymphoma (ATL) during the latency period between 30 to 50 years, it is still incurable and most of the cases end with fatal dead in the short term, the most frequent causes of death are infections. The cutaneous T- cell lymphoma is another manifestation of the virus, indicating spread. 51 year old male, with hyporexia, odynophagia, necrotic ulcerated lesions on the hands, chest and head, presents oral fungal, enters with hematemesys, hematoquesia and asthenia, anemia, nutritional and neurological disorders. Hematological tests and biopsy diagnosed LLCTA and cutaneous T-cell lymphoma cutaneous, respectively. The patient would have an unfavorable prognosis

(Rev. méd. panacea 2011; 1:89-93).
\end{abstract}

Key Words: Leukemia, adult T-cell lymphoma, HTLV-1, cutaneous lymphoma.

\section{INTRODUCCIÓN}

HTLV-1 fue el primer retrovirus patogénico humano aislado descubierto en 1980 por Poiesz y Gallo. Gessain ${ }^{(1)}$. Está presente en Japón, África central, Oceanía, el Caribe y América del Sur, estimándose de 10 a 20 millones de personas infectadas a nivel mundial. En el Perú, la prevalencia estimada varía entre $1,3-3,8 \%$ en poblaciones de diferentes grupos étnicos ${ }^{(2)}$. EI HTLV-1 es una infección frecuente en grupos de alto riesgo sexual de Pisco-Perú ${ }^{(3)}$.

El virus infecta crónicamente a los linfocitos CD4 (+) siendo los linfocitos CD8 $(+)$ reservorios. El gen tax del virus interfiere con los mecanismos de reparación del ADN, también inactiva al P53 que influiría en el desarrollo de leucemia/linfoma de células T del adulto (LLCTA) ${ }^{(4)}$, esta es una enfermedad linfoproliferativa maligna de linfocitos $T$ CD4+ maduros ${ }^{(6)}$.

Se transmite por la infusión de sangre, contacto sexual y lactancia materna por tiempo prolongado el cual se considera el factor más importante para desarrollar LLCTA $(5,21)$

Al infectarse se crean anticuerpos contra el virus y se convierten en portadores de por vida, con un riesgo entre el 1 y $4 \%$ de desarrollar alguna de las manifestaciones de la enfermedad. La LLCTA ocurre frecuentemente en personas de 40 a 60 años, con latencia estimada de 30 a 50 años ${ }^{(6)}$.

Los linfomas cutáneos es una de las manifestación del HTLV-1, indica diseminación, su incidencia mundial es de 0,5 a 1 por 100,000 habitantes entre los 40 y los 60 años y 2,2 veces más frecuentes en el sexo masculino ${ }^{(4)}$. 
Los pacientes con cáncer tienen un riesgo nutricional aumentado y una de sus consecuencias es la hipoproteinemia, causando edemas periféricos y ascitis ${ }^{(7)}$. La deficiencia de vitamina B12 causa alteraciones neurológicas entre otros, puede llevar a una degeneración subaguda combinada ${ }^{(14,18)}$, que cursa con desmielinización de las columnas laterales y posteriores a nivel espinal, la cual clínicamente se caracteriza por disestesias simétricas y alteración en la propiocepción, miopatía, neuropatía, atrofia del nervio óptico y trastornos psiquiátricos ${ }^{(9)}$

Presentamos el caso de un paciente HTLV-1 positivo, que desarrolla una LLCTA y un linfoma cutáneo de células $T$.

\section{CASO CLÍNICO}

Enfermedad actual: Varón de 51 años de edad, procedente de Ica, soltero, refiere iniciar su enfermedad hace dos meses con hematemesis, heces pastosas negruzcas, disfonía con odinofagia que no permitía la deglución de alimentos sólidos, con placas blancas en cavidad oral, tos productiva con expectoración blanquecina baja de peso e hiporexia así mismo presentó placas no dolorosas eritematosas con superficie vesicular que inician en miembros superiores luego en tórax, abdomen, genitales y en la cara, tomando el lóbulo de orejas, lesiones que evolucionan a úlceras dejando costras negras, acudió a una consulta particular y se le realizaron exámenes de sangre dando como resultado una leucemia linfoide.

Un mes después acudió al hospital por emergencia refiriendo sangrado rectal continuo, hematemesis ambos de regular cantidad y color rojo rutilante, alza térmica, hiporexia, baja de peso y debilidad muscular por lo que se decidió su internamiento. En hospitalización las deposiciones sanguinolentas persistieron por una semana, luego fueron líquidas, presentó edema en miembros inferiores, ascitis y dolor abdominal difuso. Una semana después manifestó desorientación de manera recidivante cada dos días con delirios y no podía reconocer a sus familiares, disminución de la fuerza en miembros superiores inferiores que no le permitían deambular, manifestó disminución de la audición, disminución de agudeza visual que vuelven a la normalidad dos semanas después, sensación de cuerpo extraño en ojo derecho no doloroso tos productiva purulenta con rastros sanguinolentos, posteriormente podía pasar alimentos sólidos.

El examen físico: Paciente afebril, frecuencia respiratoria de 22 por minuto, frecuencia cardiaca 118 por minuto y presión arterial de $90 / 60 \mathrm{mmHg}$, IMC: $16,9 \mathrm{Kg} / \mathrm{m}^{2}$, edemas hasta tronco; múltiples lesiones ulcerativas con centro necrótico, borde irregular eritematoso elevado de $2 \times 1,5 \mathrm{~cm}$ con salida de líquido seropurulento en dorso de ambas manos (Figura 1A), antebrazo, cuello, cuero cabelludo, pabellón auricular izquierdo este último con acartonamiento (Figura 1B) y genitales (Figura 2A). No se palpan adenopatías, se evidencia inflamación en zona supero externa de esclera del ojo derecho no doloroso, de consistencia blanda no dolorosa (Figura 2B). Presenta halitosis con placas blancas en zona tonsilar, atrofia papilar en la lengua, queilitis, disfonía permanente, vibraciones vocálicas disminuidas con roncantes difusos, auscultación de la voz no audible. Abdomen doloroso a la palpación superficial y profunda en toda su extensión, esplenomegalia. Decúbito dorsal pasivo, abatiestesia, hipopalestesia, fuerza y tono muscular disminuido, hiporreflexia osteotendinosa, reflejo plantar indiferente.

Exámenes de laboratorio: Las aglutinaciones fueron negativas. El examen parasicológico en heces mostró: ausencia de huevos y quistes. Se encontraron ooquistes de Pneumocystis Jiroveci en baciloscopía.

Tiempo de sangría 1,5 min, tiempo de protrombina $12 \mathrm{~s}$. Bilirrubinas totales $1,83 \mathrm{mg} / \mathrm{dl}$ a predominio indirecto $1,18 \mathrm{mg} / \mathrm{dl}$, DHL $310 \mathrm{u} / \mathrm{l}$ y calcio sérico $9,24 \mathrm{mg} / \mathrm{dl}$, el examen de orina no muestra alteración.

La lámina periférica muestra serie blanca con linfoblastos $90 \%$, serie roja con hipocromía y poiquilocitosis, serie plaquetaria con anisocitosis. Un nuevo examen de lámina periférica muestra presencia de linfocitos bilobulados en "pétalo de flor" y algunos en trébol diagnosticando leucemia linfocítica crónica. Se le realizó un mielograma mostrando médula ósea infiltrada por linfocitos todos maduros.

El resultado de biopsia muestra: infiltrado linfocítico a nivel de dermis e hipodermis en medio del que destacan células grandes de aspecto anaplásico, con algunas figuras mitóticas, dando como diagnóstico linfoma leucemia de células $\mathrm{T}$ del adulto. Este resultado sugiere inmunohistoquímica CD3, CD20, CD30 el cual no se realizó por razones económicas.

La ecografía abdominal mostró: esplenomegalia 16,3 x 68,1 $\mathrm{cm}$, líquido libre en abdomen, en la radiografía de tórax se aprecian múltiples opacidades nodulares tenues, mal definidas dispersas en ambos campos pulmonares.

Diagnósticos diferenciales: Dentro del diagnóstico diferencial de los problemas inmunológicos está el síndrome de inmunodeficiencia adquirida, la ataxiatelangiectasia ${ }^{(2)}$. Entre los diagnósticos diferenciales de la afección dermatológica, la micosis fungoide, el pioderma gangrenoso ampolloso asociado a paraproteinemia $\lg \mathrm{A}$, el síndrome de Sésary, la dermatitis, la sífilis secundaria y terciaria ${ }^{(10,19,20)}$, el carbunco y el ectima contagioso, el epitelioma basocelular pigmentado, el melanoma lentigo maligno ${ }^{(11,12,13)}$. 
A.

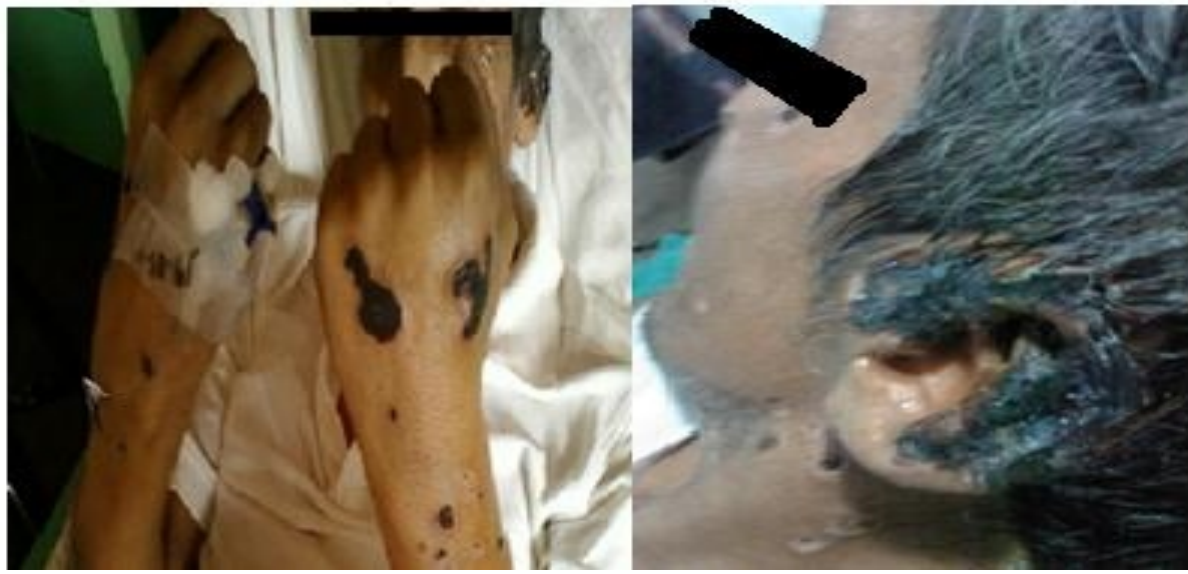

Figura 1. A. lesiones ulcero-necrótica en manos. B. Lesión auricular ulcero-necrótico.

A.

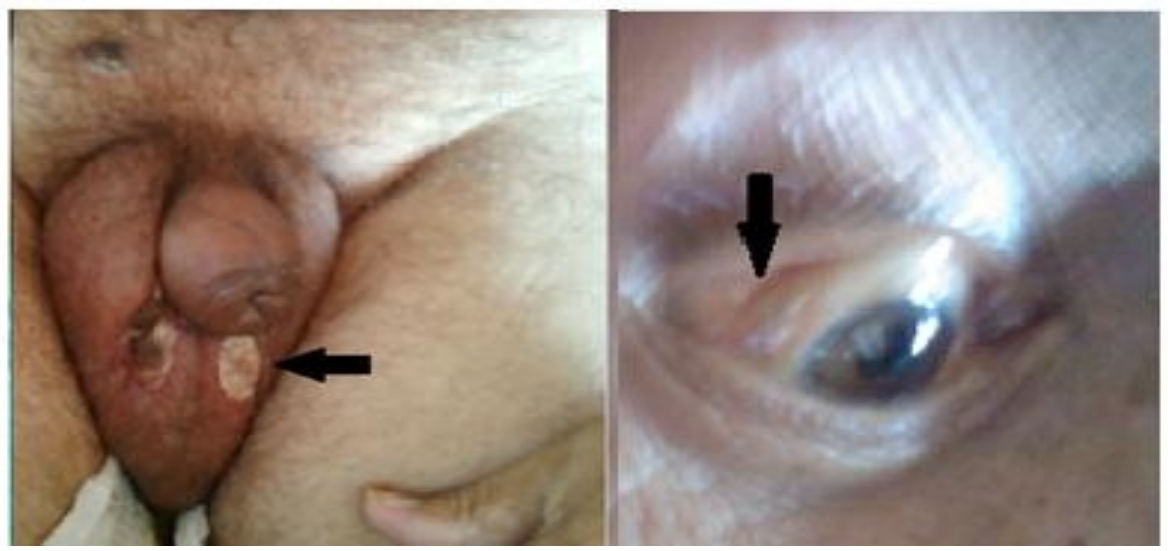

Figura 2. A. Ulcerosa y edema en escroto. B. Epiescleritis derecha.

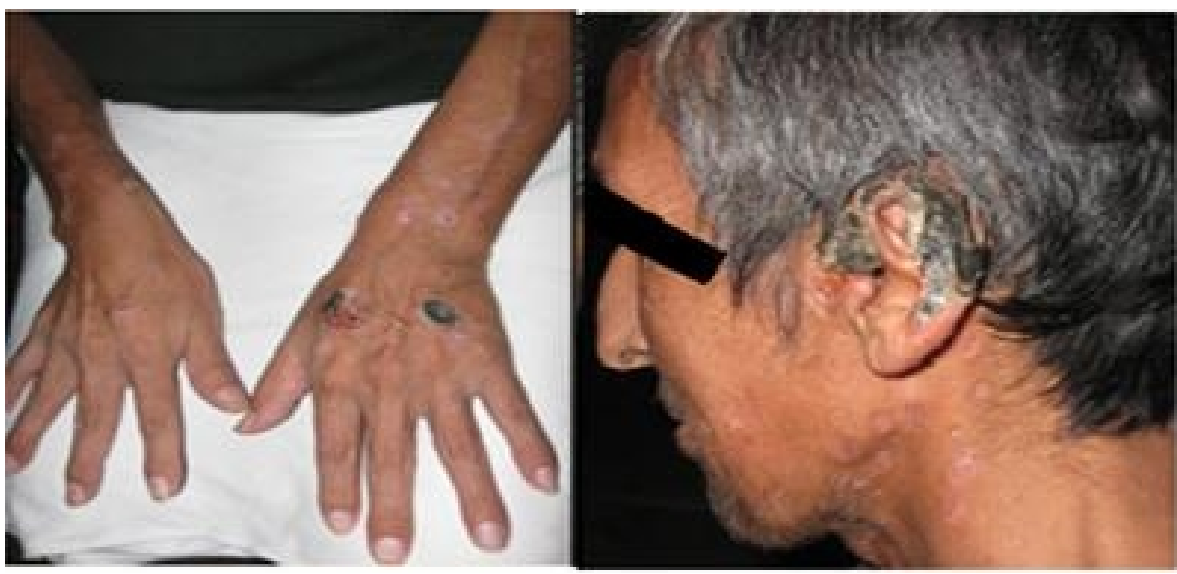

Figura 3. Remisión de lesiones en manos y pabellón auricular izquierdo. 
A.

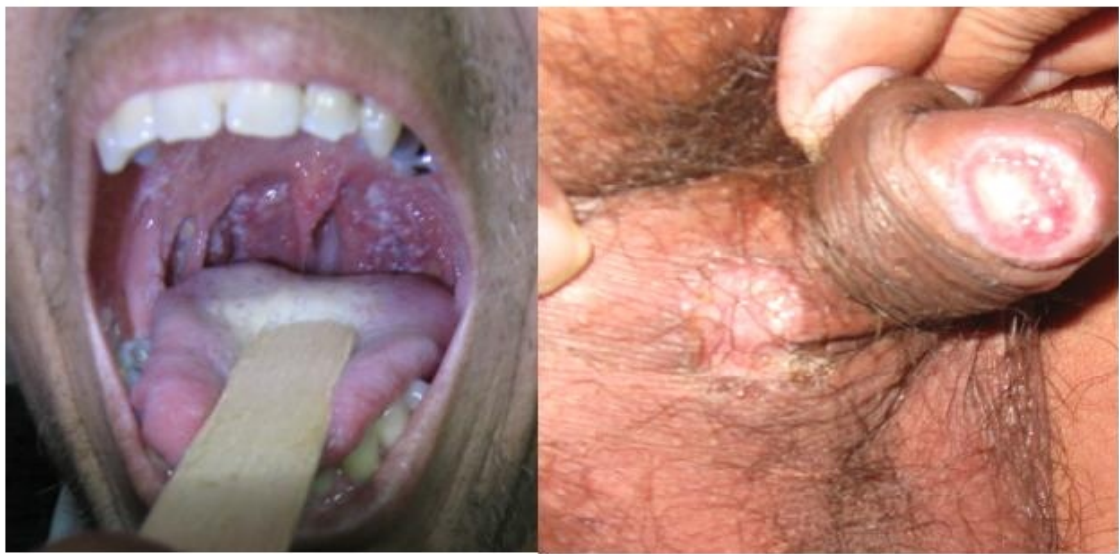

Figura 4 A. Micosis oral. B. Ulcera en glande en remisión.

Tratamiento: Los medicamentos se usaron cronológicamente según los problemas que presentó, los antibióticos se usaron para tratar la infección respiratoria (Ceftazidima $2 \mathrm{~g} \mathrm{EV} \mathrm{c/8h}$ por 5 días, Ciprofloxacino $400 \mathrm{mg}$ EV c12/h por 3 días, Amikacina $1 \mathrm{~g} \mathrm{EV} \mathrm{c/12h} \mathrm{por} 5$ días) los antifúngicos (Nistatina $500,000 \mathrm{UI}, \mathrm{VO}$ c/8h por 4 días; Fluconazol $150 \mathrm{mg}$ VO c/12h por 14 días) para el tratamiento de la micosis oral, la prednisona $50 \mathrm{mg} \mathrm{c} / 12 \mathrm{~h}$ VO por 30 días, para tratar la leucemia y Cotrimoxazol $800 / 160 \mathrm{mg} \mathrm{c/24h}$ VO por 14 días, cuando se demostró ooquistes de Pneumocystis jiroveci.

Pronóstico: Una vez desarrollado el cuadro de LCCTA, la enfermedad es incurable y usualmente mortal a corto plazo. Las causas de muerte más frecuentes son infección debido a la inmunosupresión y progresión a pesar del tratamiento (6).

Una semana después de su internamiento el paciente refiere sentirse mejor, las lesiones en piel desaparecieron considerablemente (Figura 3), presenta aún micosis oral (Figura 4A), no cumplió con la toma de clotrimoxazol y los síntomas respiratorios empeoraron posterior a su alta, presenta aún úlceras en el glande una de las cuales comunica con la uretra (Figura 4B). Presentó otra vez sangrado rectal leve y episodios de estreñimiento siendo su pronóstico desfavorable por la enfermedad de fondo.

\section{DISCUSIÓN}

El paciente resultó positivo para HTLV-1 mediante la prueba ELISA, no pudiendo confirmarlo mediante Western blot. Según la modificación de la clasificación REAL por la OMS la LLCTA se encuentra dentro de las neoplasias de células T, la LLCTA presenta cuatro formas de presentación: latente, crónica, linfomatosa y aguda, la forma crónica se presenta en un $18,5 \%$ según Shimomaya ocurre una linfocitosis absoluta con más de $5 \%$ de linfocitos $T$ anormales en sangre periférica. Puede presentarse linfadenopatía, hepatoesplenomegalia, lesiones en piel y pulmón, calcio normal y LDH hasta 2 veces por encima del valor normal superior ${ }^{(6)}$, los exámenes nos orientarían que sean improbable los otros tipos.

Los problemas con la deglución debido a la micosis orofaríngea y la anorexia ocasionaron alteraciones nutricionales por restricción crónica, podría haber llevado a una deficiencia de vitamina $B_{12} \circ$ una degeneración subaguda combinada, se debería solicitar el estudio de esta vitamina en sangre y una resonancia magnética para descartarlos respectivamente ${ }^{(9,18) \text {. }}$

La leucemia puede causar una elevación anormal de las enzimas hepáticas, trombocitopenia (17), otras manifestaciones clínicas frecuentes son astenia y adinamia debidas a anemia, el 33 y $43 \%$ tiene sangrado por trombocitopenia y esplenomegalia ${ }^{(22)}$. Podríamos atribuir la anemia, la plaquetopenia y hemorragia en el paciente por la leucemia.

El paciente fue el único de los 5 hermanos en recibir lactancia hasta los 4 años, esto podría ser la vía de contagio para adquirir el virus, se examinó a una hermana siendo el resultado no reactivo para el HTLV-1 y el no tener una pareja sexual estable también podría haber incrementado el riesgo de contagio.

Las infecciones pulmonares por Pneumocystis jiroveci son complicaciones graves en pacientes con neoplasias hematológicas, la terapia con corticoides son factores de riesgo importantes para adquirir esta enfermedad ${ }^{(2)}$.

En el Perú está difundida la costumbre de lactancia prolongada hasta los dos años, que incrementa 15,1 veces 
el contagio aunque la incidencia es baja es una enfermedad grave se recomendaría evitar la lactancia prolongada ${ }^{(21)}$.

El déficit de vitamina $B_{12}$ puede tener su origen en un inadecuado aporte vitamínico entidades patológicas , como el cáncer ${ }^{(14)}$ hipovitaminosis $B_{12}{ }^{(2,14)}$ el paciente no consumía las fuentes importantes de esta vitamina voluntariamente y por 6 meses y presento remisión de los síntomas una vez que mejoró la odinofagia, si bien no se pudo realizar un estudio del nivel de la vitamina $B_{12}$, la semiología nos orientaría a diagnosticarla, podría haber evolucionado a una degeneración sub aguda combinada, la paraparesia espástica tropical $^{(2)}$.

\section{Correspondencia:}

Max Michele Remón Torres,

Teléfono: (511) 956352792

Correo electrónico: maximito6@hotmail.com

\section{REFERENCIAS BIBLIOGRÁFICAS}

1. Mori R, Sarria C, Gonzales E, et al. Seroprevalencia del Virus Linfotrópico Humano de células T tipo 1 (HTLV-1) en pacientes con tiroiditis autoinmune. Rev Med Hered 2010; 21(4):180-186.

2. Dennis L. kasper, Eugene Braunwald, Anthony S. fauci. Principios de Medicina Interna. $17^{\mathrm{a}}$ edición: Editorial Mc Graw-Hill; 2009.

3. Garrido P, Anicama R, Gotuzzo E, et al. HTLV-I en población de alto riesgo sexual de Pisco, Ica, Perú. Rev Med Hered 1997;.8 (3) :104-107.

4. Cortez-Franco F, Quijano-Gomero E. Manifestaciones cutáneas de la infección por el virus linfotrópico $T$ humano (HTLV-I). Dermatol. Peru 2009;19 (1):49-57.

5. Diaz-Torres H. Infección por el HTLV-I en pacientes con síndromes linfoproliferativos en dos sitios centinela de Cuba. Rev Panam Salud 2010; 27 (1): 17 -22.

6. Ball de Picón E, Moreno $\mathrm{Y}$, Tachón $\mathrm{B}$, et al. Leucemia/linfoma de células $T$ del adulto asociado al virus linfotrópico humano tipo 1. Rev Dermatología Venezolana. Vol. 42, № 2, 2004.

7. Monti GR. Desnutrición hospitalaria: una patología subdiagnosticada. Rev Asoc Méd Argent 2008;121 (4):25-28.

8. Pedroso-Delgado JC, Zaldivar-Infante A. Ántrax cutáneo: reporte de un caso. Revista Archivo Médico de Camagüey 2011; 15(1): 1-7.

9. Beltran B, Palomino E, Quiñones $\mathrm{P}$, et al. Leucemia / Linfoma T del Adulto Gástrico: Reporte de cuatro casos y Revisión de la Literatura. Rev Peruana gastroenterol 2010; 30(2):153-157.

10. Rueda X, Cortés C. Linfomas cutáneos: Artículo de Revisión. Rev Asoc Col Dermatol 2008; 16(2):143-158.

11. Rengifo-Pinedo L, Cortez-Franco F, Quijano- Romero $\mathrm{E}$, et al. Sarna noruega con linfoma cutáneo en paciente HTLV-1 positivo. Dermatol peru 2007; 17 (1):49-52.

12. Perez-Carmona $L$, Vanó-Galván $S$, et al. Placa ulcerada de rápido crecimiento en una mano. Enferm Infecc Microbiol Clin. 2010; 28(7):467-468.

13. Christie C, Lepera S. Mielopatía cordonal posterior por déficit de vitamina B12 en el contexto de atrofia gástrica. Neurol Arg. 2010; 2(1):55-57.

14. Arredondo-Bruce A, Amores-Carraté J. Linfoma no Hodgkin de células T: Artículo de revisión. Revista Archivo médico de camagüey 2010; 13(3).

15. Munive-Angermüller M. Neurología neurosífilis. caso clínico y revisión bibliográfica. Revista Médica de Costa Rica y Centroamerica 2009; 66 (587):95-103.

16. Flores-Padilla $G$, et al. Linfoma no Hodgkin fulminante presentándose con acidosis láctica e insuficiencia hepática aguda. Acta Gastroenterol Latinoam 2009; 39 (2):129-134

17. Forrellat M. Deficiencia de vitamina B12: ¿tratamiento oral o parenteral?. Revista Cubana de Hematología, Inmunología y Medicina Transfusional 2009;25(1):1-8.

18. Olivares L, D'Atri G, et al. Dermatitis infectiva asociada a HTLV-1, en un adulto. Dermatología Argentina 2009: 15 (1): 49-54.

19. Ferrándiz-Pulido C, García V. Pioderma gangrenoso. Diagnóstico y tratamiento. La Dermatología en la Práctica Diaria. 2008; 23(1):24-9.

20. Alarcón-Villaverde J, Romaní F. Transmisión Vertical de HTLV-1 en el Perú. Rev Peru Med Exp Salud Publica. 2011; 28(1):101-108.

21. Ortega-Sánchez MA, Osnaya-Ortega ML. Leucemia linfoblástica aguda. Medicina Interna de México 2007; 23 (1): 26-34.

Recibido: 18/091/2011

Aceptado para publicación: 10/02/2012 